\title{
The Impact of a Robotics Summer Undergraduate Research Experience on Increasing the Pipeline to Graduate School
}

\section{Dr. Leyla F Conrad, Georgia Institute of Technology}

Leyla Conrad is the Director of Outreach in the School of Electrical and Computer Engineering (ECE) at the Georgia Institute of Technology. She has been developing and leading programs for undergraduate engineering students, ECE female and minority students, as well as high school students and teachers that supports the ECE's graduate and undergraduate recruitment and retention efforts. She is also the Education and Diversity Director of the NSF funded Materials Research Science and Engineering Center at Georgia Tech. The Center's objective is to research fabrication and characterization approaches for the implementation of epitaxial graphene as an electronic material and educate a diverse group of students at all levels in this field. Before her current appointment, she served as the Education Director of the NSF supported research centers: Packaging Research Center (1998-2006) and Center on Materials Devices for IT Research (2006-2008). In both positions, she created and implemented a highly integrated and comprehensive educational program at all levels to meet the educational needs of pre-college, undergraduate, graduate students, and industry engineers. Dr. Conrad received her Ph.D. degree in Physics from the University of Missouri - Columbia in 1990.

\section{Ms. Jill L Auerbach, Georgia Institute of Technology}

Auerbach's expertise is in program evaluation and assessment. Responsible for ABET and SACS reviews in the School of Electrical and Computer Engineering at Georgia Tech, she is also the director of the Office of Undergraduate Research in the School. Designing and implementing programs designed to increase student retention and academic engagement is a primary area of specialization.

\section{Dr. Ayanna M Howard, Georgia Institute of Technology}

Ayanna Howard is the Motorola Foundation Professor in the School of Electrical and Computer Engineering at the Georgia Institute of Technology. She received her B.S. in Engineering from Brown University, her M.S.E.E. from the University of Southern California, and her Ph.D. in Electrical Engineering from the University of Southern California in 1999. Her area of research is centered around the concept of humanized intelligence, the process of embedding human cognitive capability into the control path of autonomous systems. This work, which addresses issues of autonomous control as well as aspects of interaction with humans and the surrounding environment, has resulted in over 180 peer-reviewed publications in a number of projects - from scientific rover navigation in glacier environments to assistive robots for the home. To date, her unique accomplishments have been highlighted through a number of awards and articles, including highlights in USA Today, Upscale, and TIME Magazine, as well as being named a MIT Technology Review top young innovator of 2003, recognized as NSBE Educator of the Year in 2009, and receiving the Georgia-Tech Outstanding Interdisciplinary Activities Award in 2013. In 2013, she also founded Zyrobotics, which is currently licensing technology derived from her research lab and has released their first suite of educational technology products. From 1993-2005, Dr. Howard was at NASA's Jet Propulsion Laboratory, California Institute of Technology. Following this, she joined Georgia Tech in July 2005 and founded the Human-Automation Systems Lab. She is currently the Associate Director of Research for the Georgia Tech Institute for Robotics and Intelligent Machines. Prior to that, she served as Chair of the multidisciplinary Robotics Ph.D. program at Georgia Tech for three years from 2010-2013. 


\title{
The Impact of a Robotics Summer Undergraduate Research Experience on Increasing the Pipeline to Graduate School
}

\author{
Leyla Conrad, Jill Auerbach, and Ayanna Howard \\ School of Electrical and Computer Engineering, Georgia Institute of Technology
}

\begin{abstract}
The Summer Undergraduate Research in Engineering/Science (SURE) program, initiated in 1992, is a ten-week summer program for junior and senior level undergraduates from U.S. institutions. In 2013, the program instituted a new initiative to provide opportunities to students focused on robotics research, and as a direct consequence, interest them in opportunities available through graduate study. Robotics, as a discipline, is inherently interdisciplinary, combining all aspects of engineering and computer science necessary for designing and deploying integrated systems and solutions. Every year, eight students with diverse backgrounds are selected and paired with faculty advisors and graduate student mentors who are members of the Institute for Robotics and Intelligent Machines. In addition to conducting research during their stay, students also participate in a week-long robotics boot camp their first week, attend weekly seminars on emerging research in engineering fields, visit local industry, participate in enrichment and academic development activities, and attend social events. Students conclude the program with research presentations to their peers and faculty and graduate student mentors. During the life of the SURE program, 541 students, selected from a pool of 2,899 applicants, have participated in the program. A comprehensive assessment program for SURE has been developed and implemented. The assessment process is driven by the overall program objective to provide participants a meaningful research experience and enrichment activities to increase the likelihood that participants will attend graduate school in engineering/science. This model targets three cohorts from which data is collected. Each data source provides unique information that contributes to a comprehensive analysis of the impact and experiences of program participants and to an understanding of the academic trends of all SURE program applicants. The pre- and post-program surveys, focus group session and interviews with participants include a series of questions about students' research interests, and participants' perceived impact of SURE on research skills and planned graduate school attendance. The faculty advisor survey includes questions about the contribution the students made to their research programs, whether or not their student would succeed in graduate school, the quality of the students' oral and written project presentations, likelihood of future collaboration with the student and how the program could be improved in future years. The Longitudinal Survey of Former SURE Participants, conducted every four years, addresses the primary objective of the SURE program to motivate participating students to attend graduate school in engineering/science. Respondents are asked a variety of questions about their academic decisions after participating in the SURE program. Detailed data about graduate school attendance, degree attainment, and major is collected and analyzed. Questions are included to obtain feedback about their co-curricular activities and the environment of their undergraduate institutions. Another set of questions refer to sources of encouragement that students might have had when deciding to attend graduate school. Thus far, the program has been tremendously successful in attaining its primary objective. Collected outcome measures have shown that $76 \%$ of the students who participate in the program attend graduate school in engineering/science and 6\% attend medical school upon receiving their B.S. degree.
\end{abstract}




\section{Introduction}

A key factor for motivating students to pursue advanced degrees and careers in science and engineering is a fruitful research experience as an undergraduate [1-4]. Such experiences can be effective in helping students who exhibit uncertainty or a lack of confidence regarding attending graduate school. According to a study by SRI International $[3,4]$, undergraduate research programs can be highly effective in helping students who are uncertain about going to graduate school to clarify their intent to pursue those goals and in bolstering the certainty of those students who have already decided to do so. Many underrepresented students interested in engineering and computer science fit into these categories. While some are unsure whether to pursue graduate education at all, other students want an advanced degree, but are uncertain about the other variables involved in this decision (i.e., what school to attend, M.S. versus MBA, etc.). Ultimately, the decision of the underrepresented student to attend graduate school is profoundly affected by the amount of faculty involvement in their undergraduate career [5]. Quality interactions with faculty can have a significant impact on a student's decision to pursue graduate education, since such interaction provides the student with effective role models.

\section{Nature of Student Activities}

The overall goal of SURE is to expose students to research in engineering and science and as a direct consequence, interest them in opportunities available through graduate study. Students in the program receive subsidized on-campus housing for the duration of the program, a meal plan, a \$600 travel allowance, and full access to institutional facilities, including computer accounts, health care, recreational facilities, and the library. In addition, the participants are awarded a $\$ 5,000$ stipend. The financial incentives offered by SURE are designed to recruit some of the best available students, many of whom choose to participate despite lucrative summer employment opportunities in industry.

SURE has assembled a dedicated and supportive cadre of faculty advisors who regularly involve undergraduate students in their research during the academic year. Many of the SURE faculty returned every summer to serve as research advisors. This group of very accomplished educators and researchers has included NSF CAREER award winners, Young Investigator Awardees, and winners of several other prestigious national and international awards. This group of very accomplished and diverse faculty advisors has proven to be excellent resources for SURE students because they share two critical viewpoints: (1) the importance of undergraduate research in encouraging graduate study; and (2) the need for all segments of society to participate in engineering and science careers. SURE ensures the development of interaction between the participants and the faculty by facilitating direct, one-on-one relationships. This enhances the research experience of the undergraduates by providing practical examples of the typical day-today interactions that take place between professors and graduate students [6]. In addition to faculty advisors, SURE students are also assigned graduate student research mentors. Pairing undergraduate students with graduate students closer to their peer group eases student communication and helps alleviate any discomfort that the undergraduates might feel as they acclimate themselves to the research environment [7]. In order to provide a cohesive research experience, graduate mentors are advisees of the faculty. In this way, mentors are capable of 
dealing with the students' day-to-day questions and concerns related to general aspects of campus and community life. During the first week, students participate in a 4-day prep course "Fundamentals of Robotics" and learn the basics of robotics, including mechanics, embedded programming, control, and perception. The prep course is not designed to teach everything about robotics but do provide sufficient background so the students know where and when to look for answers related to their robotics projects, thus getting them better prepared for their research projects. Participants actively start working with their mentors at the beginning of the second week.

Student communication and skill development are enhanced by several group activities such as meetings, seminars, workshops and field trips. During weeks 2-10, students broaden their knowledge and become better acquainted with research through weekly technical seminars on state-of-the-art topics. Only the robotics-related seminars that were offered during 2014 are provided in Table 1.

Table 1: The 2014 SURE Robotics Seminar Series

\begin{tabular}{|l|l|l|}
\hline Date & Topic & Speaker \\
\hline \hline Week 2 & "Mobile Robots for Personal Assistance" & Prof. Charles C. Kemp \\
\hline Week 5 & "Rehabilitation and Therapy Robotics" & Prof. Ayanna Howard \\
\hline Week 6 & "Monte Carlo Algorithms for Robot Navigation" & Prof. Frank Dellaert \\
\hline Week 7 & $\begin{array}{l}\text { "Wrapping Your Brain Around the Many Miracles of the } \\
\text { Microelectronics Revolution" }\end{array}$ & Prof. John D. Cressler \\
\hline Week 9 & "Designing Interactions for Robot Learners" & Prof. Andrea Thomaz \\
\hline Week 10 & End of Program Project Presentations & Participants \\
\hline
\end{tabular}

Status meetings or professional development workshops were held every Tuesday morning. Topics that were covered during the 2014 program are provided in Table 2. At the status meetings, each participant reports orally what he/she has accomplished in the past week and his/her plans for the current week. Workshops were organized to provide participants fundamental and professional skill development through interactive exercises to better prepare them for a successful research experience and tools for graduate school. In addition, three fundamental areas - communication, investigation and documentation - were emphasized in these workshops [8-10]. Participants were trained on ethics related subjects by completing the online Responsible Conduct of Research $(R C R)$ course at the Collaborative Institutional Training Initiative site, www.citiprogram.org. All the participating students also received two sessions each of three-hour in-class GRE preparation.

Table 2: 2014 SURE Robotics Weekly Meetings and Workshops

\begin{tabular}{|l|l|l|}
\hline Date & Topic & Speaker \\
\hline \hline Week 1 & $\begin{array}{l}\text { Research Methods Orientation and Literature } \\
\text { Review [11,12] }\end{array}$ & Dr. Tom Gaylord \\
\hline Week 2 & "Effective Communication Skills" & Dr. Lisa Rosenstein \\
\hline Week 3 & Status Meeting & SURE Coordinator \\
\hline Week 4 & "Time Management Strategies" & Dr. Shannon Dobranski \\
\hline Week 5 & Status Meeting & SURE Coordinator \\
\hline
\end{tabular}




\begin{tabular}{|l|l|l|}
\hline \multirow{2}{*}{ Week 6} & "Life of a Graduate Student" & Graduate Student Panel \\
\cline { 2 - 3 } & GRE Prep Course I & Princeton Review Instructor \\
\cline { 2 - 3 } & GRE Prep Course II & Princeton Review Instructor \\
\hline Week 7 & Status Meeting & SURE Coordinator \\
\hline Week 8 & "Applying to Graduate School" & Dr. Lisa Rosenstein \\
\hline Week 9 & $\begin{array}{l}\text { "Show me the Money: Funding for Graduate } \\
\text { School" }\end{array}$ & Dr. Kathryn Meehan \\
\hline Week 10 & Status Meeting & SURE Coordinator \\
\hline
\end{tabular}

Participants tour at least two industry sites during their stay. Sites that were visited in 2014 included Lockheed-Martin, Cisco, and Georgia Tech's Food Processing Technology facilities. A working relationship has been established with Lockheed-Martin and Cisco's outreach and community relations teams, and they provide an overview presentation followed by 3-4 hours long tour. A group photo taken last summer by the Lockheed-Martin photographer is shown in Fig. 1.

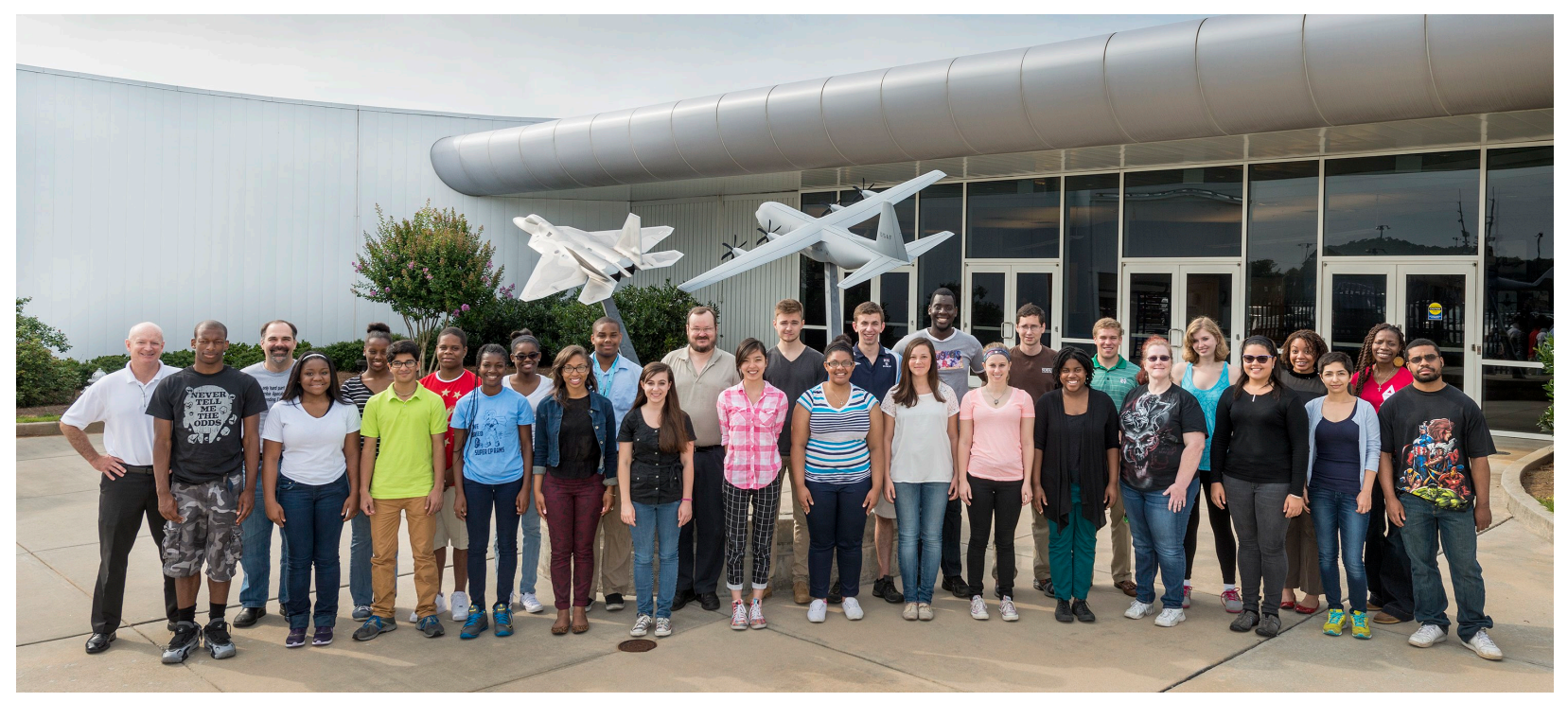

Figure 1 - SURE Robotics 2014 participants at the Lockheed-Martin plant located at Marietta, GA

The social and collegial development of the SURE participants is encouraged and facilitated by group outings such as trips to museums, athletic events, Six Flags, white water rafting (see Figure 2) or concerts in the Atlanta area. 


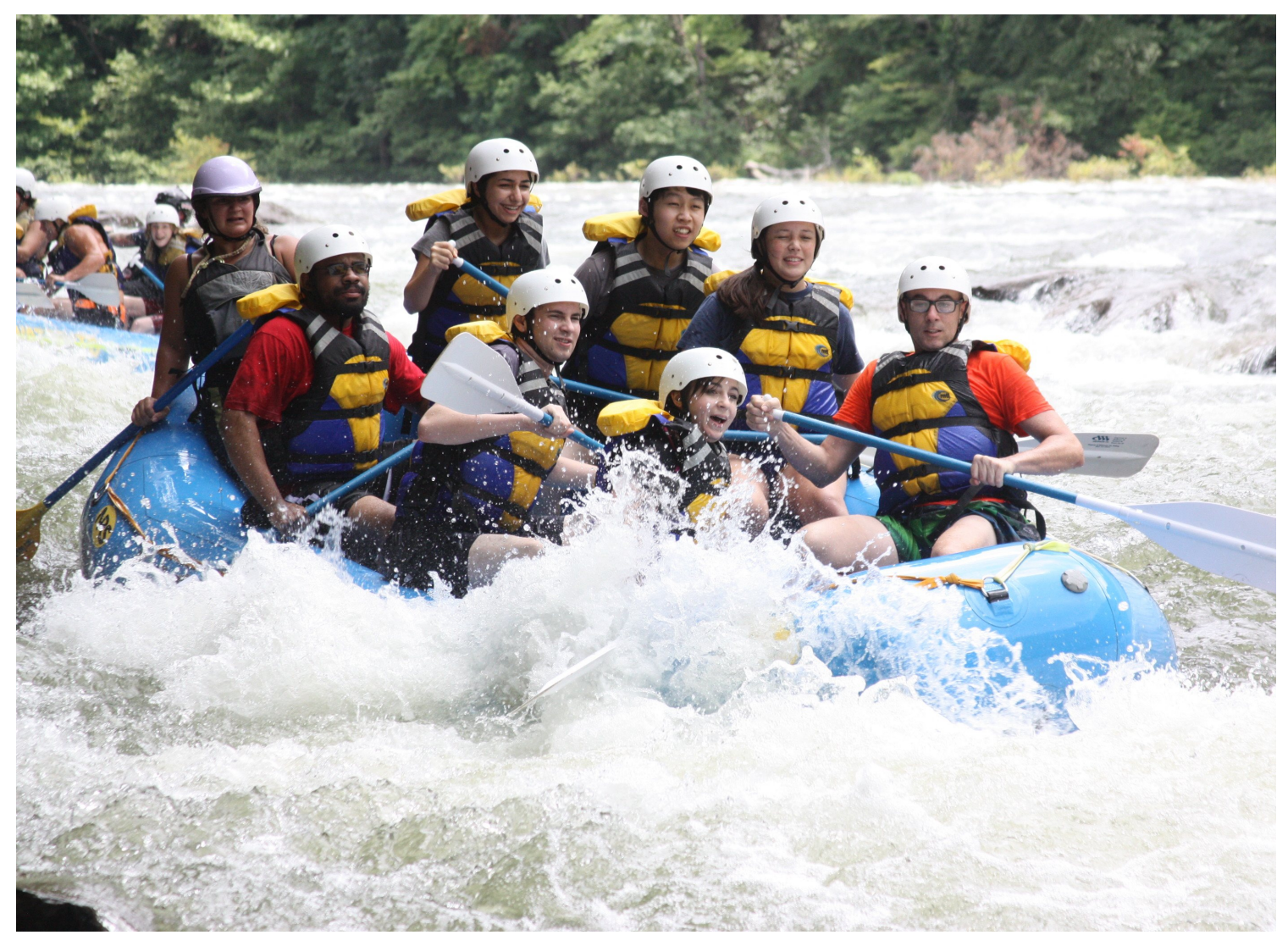

Figure 2 - SURE Robotics 2014 participants at the white water rafting social outing

\section{Student Recruitment and Selection}

The SURE Robotics program is advertised electronically via its own Internet home page (http://www.sure.robotics.gatech.edu). General program information, as well as an on-line application, is available at this site. The program is also listed on the NSF and the Institute for Broadening Participation web sites. In addition to these, students are recruited by announcements and advertisement through several national engineering organizations, including the National Society of Black Engineers (NSBE) and the Society of Hispanic Professional Engineers (SHPE) as well as e-mail announcements sent to faculty teaching at HBCUs and other minority serving institutions. In 2014, the SURE Robotics program received 78 applications where 39\% were from minority and 35\% from female students. More than $90 \%$ of the applications came from students attending higher education institutions other than the home institution, and quite a large portion of them from undergraduate institutions and two-year colleges where research opportunities for undergraduates are typically less available.

Recruitment takes place during October through February of each year, and student applications are due March 25. Criteria for selection consist of the student's academic record (GPA, transcript, and academic honors), a statement of interests, and one letter of recommendation from a faculty member at the student's home institution. Once the qualifying applicants are identified by the selection committee, application packages are posted on the Georgia Tech internal web site "T-square" along with a preliminary ranking and a summary statement providing a snapshot of the student's related skill sets and experiences. The participating faculty advisors are then 
given access to the site and invited to select the student they want to work with. Once the applicants are selected and offer letters are sent out, each faculty advisor contacts the student he/she is going to advise, provides more information about the research project and any reading material associated with it. Alternates are selected in the event that any of the initial candidates decline the invitation to participate.

Tables 3 and 4 provide the demographic profile of SURE applicants and participants in the past twenty years, from 1992-2014. Since its inception, a total of 541 students have participated in the program.

Table 3: Applicant/Participant Ethnicity from 1992-2014

\begin{tabular}{|l|l|l|}
\hline Ethnicity & Applied & Selected \\
\hline \hline $\begin{array}{l}\text { African } \\
\text { American }\end{array}$ & $1965(68 \%)$ & $387(72 \%)$ \\
\hline $\begin{array}{l}\text { Hispanic } \\
\text { American }\end{array}$ & $404(14 \%)$ & $95(18 \%)$ \\
\hline Native American & $6(0 \%)$ & $1(0 \%)$ \\
\hline Other & $514(18 \%)$ & $58(10 \%)$ \\
\hline TOTAL & 2,899 & 541 \\
\hline
\end{tabular}

Table 4: Applicant/Participant Gender from 1992-2014

\begin{tabular}{|l|l|l|}
\hline Gender & Applied & Selected \\
\hline \hline Male & $1572(54 \%)$ & $321(59 \%)$ \\
\hline Female & $1295(45 \%)$ & $220(41 \%)$ \\
\hline Not known & $32(1 \%)$ & \\
\hline TOTAL & 2,899 & 541 \\
\hline
\end{tabular}

\section{Program Evaluation}

The assessment process is driven by the overall program objective to provide participants a meaningful research experience and to increase the likelihood that participants will attend graduate school in engineering. This model identifies three cohorts from which data is collected and includes active participants, SURE faculty advisors and alumni participants. Each of these respondent groups provide unique information that contributes to a comprehensive analysis of the impact and experiences of program participants and to an understanding of the academic trends of all SURE program applicants. A brief overview of the data sources, assessment goals, and collection methods for annual evaluation and participant tracking are as follows:

1. An annual "SURE Robotics Participant Pre-program Survey" is distributed on the first day of the program at the orientation to determine program expectations, undergraduate research experiences, and attitudes towards graduate school attendance.

2. An annual "SURE Robotics Participant Focus Group Session" is administered midway to determine if the REU program is progressing satisfactorily and as planned. 
3. An annual "SURE Robotics Participant Post-program Survey" is distributed on the last day of the SURE program to assess the quality of program components, extent expectations were met, and initial reactions to likelihood of graduate school attendance.

4. An annual "Faculty Advisor Post-program Survey" is electronically distributed at the end of the program to measure the contribution that students made to their research programs, evaluate the quality of the students' oral and written project presentations, plans for future student-mentor interaction and provide any recommendation for program improvement.

5. Exit Interviews with the participants are scheduled and conducted by the Program Evaluator six months after the conclusion of the program. Interview questions focus on how well the REU experience met the program goals. Since a primary program goal is to encourage graduate school attendance in STEM fields, participants will be asked how and why various program elements may influence this decision.

6. A "Longitudinal Survey of Former SURE Program Participants" that uses multiple distribution methods in order to maximize response rate and to track stability of academic field, graduate school attendance/degree completion, research activities, perceptions about the benefits and limitations of the program, and asks for any suggestions for improvements to the program. This survey was administered for the first time in 2005 and then in 2009 and most recently in 2014.

The pre- and post-program surveys include a series of questions about participants' perceived impact of SURE on planned graduate school attendance and research interests. Using a Likert response scale, students rank the perceived level of impact. The response categories for the program effectiveness questions ask respondents to rate various program components on a 4point quality scale and students are asked to answer questions about the appropriate number of program activities.

Pre-program Evaluation: The pre-program survey is administered on the first day of the program. Highlights from the 2014 pre-program survey findings indicated that the $89 \%$ participants' primary reason for attending the SURE Robotics program was to pursue their particular research interest and learn new research skills. The other primary reason for attending the SURE Robotics program was to learn more about graduate school at the host institution (78\%). When asked about the importance of the various SURE Robotics program components, $78 \%$ participants indicated that having exposure to Georgia Tech research faculty was extremely important. Attending seminars on state-of-the-art research topics and receiving training on technical writing were selected by $78 \%$ as moderately important components. The least important component of the program according to the majority of the participants $(78 \%)$ was going on group social outings.

Post-program Evaluation: The post-program survey is administered on the last day of the program. A major component of this survey is to measure perceptions of gains from the REU experience in different areas, including gains in personal growth and research-related skills and knowledge. According to the findings of the 2014 post-program survey, SURE Robotics participants reported significant gains in:

1. Understanding the theory and concepts that guided their research (78\%)

2. Using problem solving skills in the research process $(78 \%)$ 
3. Understanding what everyday research is like (67\%)

4. Planning and preparing for graduate school $(67 \%)$

5. Identifying limitations of research methods and designs (56\%)

6. Confidence in their ability to do well in future technical/scientific courses $(56 \%)$

7. Examining career choices based on their degree (56\%)

8. Working with new/updated computer applications $(56 \%)$

According to the findings of the post-program survey only one major minimal gain was reported in: Defending an argument/position when asked research related questions (44\%)

Other highlights from the post-program surveys include the noteworthy finding that $78 \%$ of the participants indicated that the SURE experience increased their desire to attend graduate school compared to just one participant who said that the experience had no impact either way and one participant who said it lessened his/her desire to attend graduate school. An overall measure of satisfaction with the experience is evidenced where all the participants said they would strongly recommend SURE Robotics to other students. When asked if the SURE experience enhanced their understanding of graduate student life, $67 \%$ of the participants said significantly enhanced understanding and $33 \%$ indicated moderate enhancement. This finding is important because of the need to expose students to the environment and demands of graduate school life. The above data indicates that SURE Robotics has been a resounding success in meeting the primary objectives of the program.

Faculty Advisor Feedback: The SURE Robotics faculty survey is administered to the faculty advisors within two weeks of the conclusion of the program. According to the responses, a majority of faculty advisors rated the quality of their SURE students "excellent" on the following attributes: willingness to work on the assigned project (100\%), ability to fit in at the lab (100\%) motivation to learn about research $(100 \%)$, preparation to work on research $(63 \%)$, timeliness to complete assignments $(63 \%)$, and resourcefulness to figure things out $(63 \%)$. All of the faculty advisors said they would provide a recommendation for the student's graduate school application. In addition, faculty advisors were eager to keep in touch with SURE students and planned to contact them in the coming year.

\section{Participant Tracking}

The Longitudinal Survey of Former SURE Participants addresses the primary objective of the SURE program to motivate participating students to attend graduate school in engineering. The study was conducted in 2005 on the population of students who were participants in the 19992003 SURE programs, and then in 2009 on the 2003-2007 participants, and then in 2014 on the 2008-2011 participants. Thus, all respondents had been out of the SURE program for at least two years. Most participants were rising juniors or seniors at the time they were in the SURE program, thus, two years is a reasonable interlude to provide students time to complete their baccalaureate studies and enter a graduate program. However, the participants who were still pursuing their B.S. degrees during the 2005 implementation were contacted again in 2009, similarly the ones pursuing their B.S. degrees during the 2009 implementation were contacted again in 2014. 
Respondents were asked a variety of questions about their academic decisions that occurred after participating in the SURE program. Detailed data about graduate school attendance, degree attainment, and major was collected. Questions were included to obtain feedback about their cocurricular activities and the environment of their undergraduate institutions. Another set of questions referred to sources of encouragement that students might have had when deciding to attend graduate school. Finally, a series of questions that asked about specific experiences during SURE were included [2,13]. The foundation of this approach was to determine if SURE participants subsequently chose to attend graduate programs of study and what factors may be associated with this decision specifically:

- Do co-curricular activities at the students' home institutions - such as membership in professional organizations, co-op participation, or other undergraduate research activities - play a role in graduate school attendance?

- What are the influences of students' peers and family on the decision to attend graduate school?

- What role did the SURE program in general play in the decision to attend graduate school?

- What effect does the mentoring provided by the SURE program have on the decision to attend graduate school?

The response rates to each of the surveys were $59 \%$ in $2005,65 \%$ in 2009 , and $75 \%$ in 2014 . A total of 71 responses were obtained in 2005, of which 62 had completed baccalaureate programs of study. A total of 88 responses were obtained in 2009, of which 86 had completed baccalaureate programs of study. Similarly, a total of 92 responses were obtained in 2014, of which 84 had completed baccalaureate programs of study. Basic demographic and academic characteristics of these respondents who had completed their B.S. degrees since participating in the SURE program are presented in Table 5.

Table 5: Respondents' Demographic and Academic Data

\begin{tabular}{|l|c|c|c|}
\hline & $\begin{array}{c}\text { \% Respondents } \\
\text { (2005 Study) }\end{array}$ & $\begin{array}{c}\text { \% Respondents } \\
\text { (2009 Study) }\end{array}$ & $\begin{array}{c}\text { \% Respondents } \\
\text { (2014 Study) }\end{array}$ \\
\hline \hline Gender & & & 45 \\
\hline Male & 52 & 60 & 37 \\
\hline Female & 48 & 40 & 18 \\
\hline No answer & & & \\
\hline Ethnicity & & & 45 \\
\hline African American & N/A & 76 & 19 \\
\hline Hispanic American & N/A & 15 & 18 \\
\hline Other (White or Asian) & & 9 & 18 \\
\hline No answer & & & \\
\hline $\begin{array}{l}\text { Type of Undergraduate } \\
\text { Institution }\end{array}$ & 45 & 27 & 26 \\
\hline Minority Serving Institution & 56 & 67 & 49 \\
\hline Research/Doctoral & 17 & 8 & 7 \\
\hline Master's & & & \\
\hline
\end{tabular}




\begin{tabular}{|c|c|c|c|}
\hline Baccalaureate & 14 & 14 & 10 \\
\hline No answer & & & 8 \\
\hline \multicolumn{4}{|l|}{ Undergraduate Major } \\
\hline Science & 29 & 14 & 24 \\
\hline Engineering & 71 & 86 & 67 \\
\hline Other or no answer & & & 9 \\
\hline \multicolumn{4}{|l|}{ Graduate School Status } \\
\hline Completed Ph.D. Degree & 0 & 6 & 6 \\
\hline Enrolled in Ph.D. Program & 34 & 34 & 37 \\
\hline Enrolled or earned medical degree & & & 6 \\
\hline Terminal Masters Degree & 15 & 20 & 20 \\
\hline Enrolled in Masters Program & 24 & 16 & 13 \\
\hline $\begin{array}{l}\text { Completed B.S. Degree and did } \\
\text { not Enroll in Any Graduate } \\
\text { Program }\end{array}$ & 27 & 24 & 18 \\
\hline $\begin{array}{l}\text { Went to Graduate School (for } \\
\text { either MS or PhD degree) }\end{array}$ & 73 & 76 & 76 \\
\hline
\end{tabular}

The two most noteworthy results are:

1. $\mathbf{7 3 - 7 6 \%}$ of the students who participated in the program during 1999-2011 and responded to the survey went to graduate school excluding the medical school.

2. 34-45\% of the students who participated in the program during 1999-2011 and responded to the survey were enrolled in a Ph.D. program or received a Ph.D. degree at the time of the study.

These figures are extremely high when compared to the nationwide low graduate enrollment of minority students in engineering [3]. Therefore, this is a significant accomplishment for the SURE program. Furthermore, of the students who were enrolled in a Ph.D. program, half of them attended graduate school at Georgia Tech. This shows that the SURE program also acts as an effective graduate recruitment activity.

Based on the 2009 survey findings, SURE students who attended graduate school reported more frequent encouragement from family and friends compared to their non-graduate school counterparts. An interesting finding is the apparent influence of the SURE program on participants' consideration of graduate school. While $49 \%$ of the 2009 respondents agreed that they were interested in attending graduate school before their SURE experience, $77 \%$ were interested after the experience. Similarly, $82 \%$ of the 2014 respondents reported that SURE had a major or moderate influence on the respondent's decision to attend graduate school. Thus, the experience of the program reinforces the choice to attend graduate school among those predisposed to do so and also attracts those who were previously not interested. In addition, this data indicates that regardless of whether or not the respondent eventually attended graduate school, participants agreed that the SURE experience was beneficial to their careers; $93.3 \%$ of graduate school attendees, and $88.2 \%$ of non-attendees. This suggests that even though participation in the SURE program contributes to the increase of graduate enrollment, participants find the experience helpful to their future careers regardless of whether they attend 
graduate school.

\section{Conclusion}

The SURE program that has existed since the summer of 1992 and funded by the NSF REU Site Program has been designed to expose qualified students, predominantly minority or female, to engineering/science research at Georgia Tech. Students, who are paired with both a faculty advisor and graduate student mentor, undertake meaningful research projects, visit local industry, and attend weekly seminars and skill development workshops. Thus far, the program has been tremendously successful in attaining its objectives. It has been shown that about $76 \%$ of the students who participated in the program attended graduate school upon receiving their B.S. degrees. Although underrepresented minorities only account for a very low overall percentage of advanced degree recipients in engineering, over the past decade, the number of advanced degrees awarded to persons in these segments of the population has increased [14]. SURE and programs like it have played a pivotal role in this trend.

\section{Acknowledgements}

The authors would like to express their gratitude to the National Science Foundation (award number EEC-1263049) for supporting the SURE Robotics program.

\section{Bibliography}

1. W.D. Compton, "Encouraging Graduate Study in Engineering," J. Eng. Education, 249255, 1995.

2. R. Morley, J. Havick, and G. May, "An Evaluation of the Georgia Tech Summer Undergraduate Program of Research in Electrical Engineering for Minorities," J. Eng. Education, vol. 87, no. 3, July, 1998.

3. S. Russell, "Evaluation of NSF Support for Undergraduate Research Opportunities," Draft Synthesis Report, SRI Project Number P16346, July, 2006.

4. S.H. Russell, M.P. Hancock, and M. McCullough, "The Pipeline: Benefits of Undergraduate Research Experiences," Science, vol. 316, pp. 548-549, April, 2007.

5. V. Tinto, "Dropout from Higher Education: A Theoretical Synthesis of Recent Research," Review of Educational Research, vol. 45, no. 1, 1975.

6. E. Barnes, "Getting Minorities into Ph.D. Pipeline Requires Active and Early Intervention, Say Experts," Black Issues in Higher Education, July, 1992.

7. J. Fairley, L. Conrad, and G. May, "The Importance of Graduate Mentors in Undergraduate Research Programs," Proc. 2007 ASEE Conference and Exposition, Honolulu, HI, June, 2007.

8. D.J. Lilja, "Suggestions for Teaching the Engineering Research Process", Proc. 1997 ASEE Conference and Exposition.

9. J. Fairley, J. Auerbach, A. Prysock, L. Conrad, G. May, "Teaching Research Skills in Summer Undergraduate Research Programs", Proc. American Society for Engineering Education 115th Annual ASEE Conference \& Exposition, Pittsburgh, PA, 2008. 
10. Ashley N. Johnson, Jill Auerbach, Adrianne Prysock, Leyla Conrad and Gary S. May, "Development and Implementation of Academic Enrichment Activities for REU Students," Proc. 2009 ASEE Conference and Exposition, San Antonio, TX, June 2009. 11. D. Taylor and M. Procter, "The Literature Review: A Few Tips On Conducting It", Writing Support, J. Plotnick, Editor. University of Toronto Toronto. 2007.

12. G. Stacks and E. Karper, The Online Writing Lab at Purdue University. 2001, Purdue University: Lafayette.

13. J. Auerbach, C. Davis, J. Gordon, and G. May, "A Comprehensive Examination of the Impact of the Summer Undergraduate Research Program on Minority Enrollment in Graduate School," Proc. 2007 ASEE Conference and Exposition, Honolulu, HI, June, 2007.

14. Women, Minorities, and Persons with Disabilities in Science and Engineering: 2011 www.nsf.gov/statistics/wmpd/ 